\title{
Dual Encoding of Muscle Tension and Eye Position by Abducens Motoneurons
}

\author{
María A. Davis-López de Carrizosa, ${ }^{1}$ Camilo J. Morado-Díaz, ${ }^{1}$ Joel M. Miller, ${ }^{2}$ Rosa R. de la Cruz, ${ }^{1}$ and Ángel M. Pastor ${ }^{1}$ \\ ${ }^{1}$ Departamento de Fisiología y Zoología, Facultad de Biología, Universidad de Sevilla, 41012-Sevilla, Spain, and ${ }^{2}$ Smith-Kettlewell Eye Research Institute, \\ San Francisco, California 94115
}

Extraocular muscle tension associated with spontaneous eye movements has a pulse-slide-step profile similar to that of motoneuron firing rate. Existing models only relate motoneuron firing to eye position, velocity and acceleration. We measured and quantitatively compared lateral rectus muscle force and eye position with the firing of abducens motoneurons in the cat to determine fundamental encoding correlations. During fixations (step), muscle force increased exponentially with eccentric eye position, consistent with a model of estimate ensemble motor innervation based on neuronal sensitivities and recruitment order. Moreover, firing rate in all motoneurons tested was better related to eye position than to muscle tension during fixations. In contrast, during the postsaccadic slide phase, the time constant of firing rate decay was closely related to that of muscle force decay, suggesting that all motoneurons encode muscle tension as well. Discharge characteristics of abducens motoneurons formed overlapping clusters of phasic and tonic motoneurons, thus, tonic units recruited earlier and had a larger slide signal. We conclude that the slide signal is a discharge characteristic of the motoneuron that controls muscle tension during the postsaccadic phase and that motoneurons are specialized for both tension and position-related properties. The organization of signal content in the pool of abducens motoneurons from the very phasic to the very tonic units is possibly a result of the differential trophic background received from distinct types of muscle fibers.

\section{Introduction}

Extraocular muscles (EOMs) move the eye against loads presented by the globe and other orbital tissues including the EOMs. Unlike skeletal motor systems, the extraocular system does not deal with varying external loads so muscle tension has a more direct relationship to motoneuronal discharge such that firing rates might be described by eye position and its time derivatives given the relative ease of measuring eye position (Robinson, 1963). This simple view is compromised by the fact that eye rotation does not reflect the differences in tensions of antagonistic EOM pairs and thereby represents only approximately half of the degrees-of-freedom in muscle tension. In addition, this reduced signal is expressed through the low-pass filter of the orbital mechanics that makes it more likely muscle tension contains aspects of ensemble motoneuron firing rates that do not appear in eye position (Miller and Robins, 1992; Miller et al., 2002). In this study, we measured both eye position and EOM tension, to determine which aspects of spontaneous motoneuronal firing are related to EOM tension compared with eye position, and whether motoneurons could be divided into functional subtypes. Extraocular motoneurons were first described as belonging to sev-

Received 0ct. 14, 2010; revised Nov. 9, 2010; accepted Dec. 9, 2010.

This work was partly supported by grants from Ministerio de Ciencia y Tecnologia (MCYT)-FEDER (BFU200907121) and MCYT-TRACE (PET2008-0226), by Fundación Eugenio Rodríguez Pascual and Junta de Andalucía (P09(VI-4617) to A.M.P., and by National Institutes of Health-National Eye Institute Grant EY015314 to J.M.M. M.A.D.L.C. was a scholar of the FISS in Spain.

Correspondence should be addressed to Dr. Angel M. Pastor, Dept. de Fisiología y Zoología, Facultad de Biología, Avda. Reina Mercedes, 6, 41012-Sevilla, Spain. E-mail: ampastor@us.es.

DOI:10.1523/JNEUROSCI.5416-10.2011

Copyright $\odot 2011$ the authors $\quad 0270-6474 / 11 / 312271-09 \$ 15.00 / 0$ eral distinct classes (tonic, tonic-phasic, and phasic) attending to their basic modes of firing (Henn and Cohen, 1972; Sterling and Gestrin, 1975; Dieringer and Precht, 1986), and consensus was reached later in a single tonic-phasic class (Fuchs and Luschei, 1970; Robinson, 1970; Schiller, 1970; Delgado-García et al., 1986a; Fuchs et al., 1988; Pastor et al., 1991), and recently as two classes driving singly innervated, and multiply innervated fibers (Büttner-Ennever et al., 2001, 2002). The generally accepted description of ensemble motoneuronal behavior associated with saccadic eye movement distinguishes a burst (pulse) of innervation proportional to the velocity of the saccade, by a decay (slide) in firing rate that finally settles to a new level (step) of innervation appropriate to the new fixation position (Optican and Miles, 1985; Goldstein and Robinson, 1986). The pulse-slide-step model of Optican and Miles (1985) assumes afferent input to motoneurons consists of summing 3 signals proportional to (1) the burst neuron discharge, (2) the tonic discharge arising as the integral of the burst, and (3) a low-pass filtered copy of the burst responsible for the slide. Because no input to extraocular motoneurons is known to contain a pure slide signal, the source for this signal has been assumed to arise from the neural integrator (Pastor et al., 1994; Aksay et al., 2001, 2007) (Fig. 1A). To characterize the signals carried by motoneurons, we measured the discharge characteristics of abducens motoneurons while recording both eye position and also the lateral rectus muscle tension. We show for the first time that motoneurons encode signals related to both eye position and muscle tension and that the slide is encoded as a distinct signal. Our results indicate that the tonic and phasic signals are distributed as a continuum of individually unique motoneuron sensitivities throughout the abducens nu- 

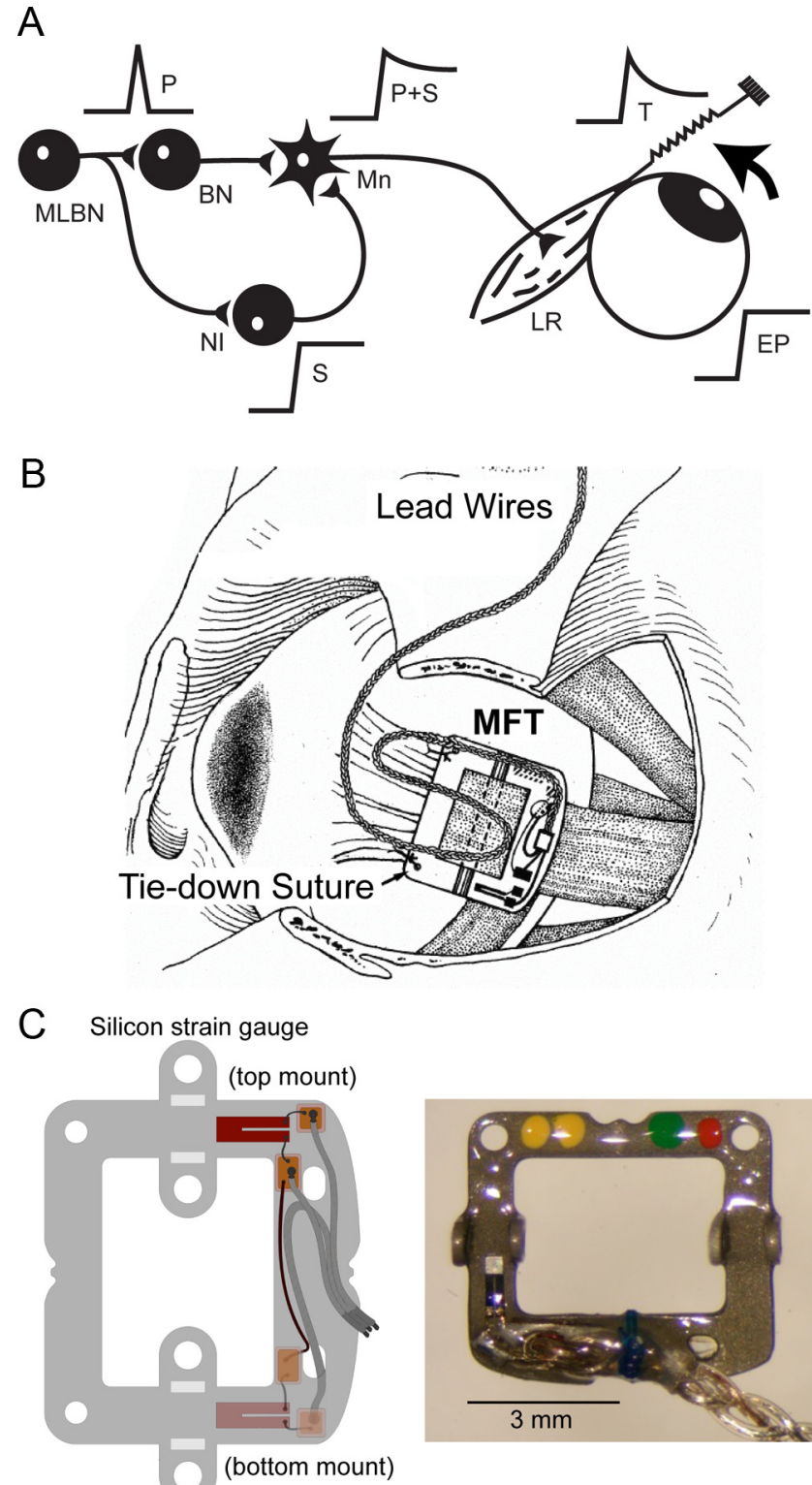

Figure 1. $A, A$ phasic firing $(P$, pulse) arises from reticular neurons [medium lead burst neurons (MLBN)] and combines $(P+S)$ in the motoneuron $(M n)$ with a tonic signal $(S$, step) arising from the neural integrator (NI). Firing rate after the saccade does not correlate well with EP due to the postsaccadic slide in firing. Lateral rectus (LR) muscle tension $(T)$ demonstrates a transient rise, a slide, and a persistent component, whereas EP lacks the slide. $\boldsymbol{B}$, Drawing of the implanted MFT in the lateral rectus tendon. $C$, Schematics of the half-Wheatstone bridge mounted with two strain gauges glued by opposed faces to the buckle for temperature compensation (left). Picture of the actual MFT (right).

cleus. A preliminary report has been published previously (Pastor et al., 2009).

\section{Materials and Methods}

Surgical procedures. Experiments were performed on adult female cats weighing 2.3-2.5 kg, obtained from authorized suppliers (Servicio de Animales de Experimentación, Universidad de Córdoba, Spain). Three animals were surgically prepared for chronic recording of eye position and lateral rectus muscle force as well as extracellular recording of abducens motoneurons. All procedures complied with regulations concerning chronic animal experiments (R.D. 120/2005 BOE 252/34367-91, 2005).

Animals received a vagolytic injection of atropine sulfate $(0.5 \mathrm{mg} / \mathrm{kg}$, i.m.) and were then anesthetized with sodium pentobarbital $(35 \mathrm{mg} / \mathrm{kg}$, i.p.). A stereotaxic frame was used to implant bipolar stimulating electrodes in the left abducens nerve and the right medial longitudinal fascicle. Coils, consisting of 2 turns of Teflon-insulated stainless-steel wire (AS-631, Cooner Wire), were implanted on the sclera of both eyes and their leads passed subcutaneously toward the scalp. An acrylic resin recording chamber was constructed over a $5 \mathrm{~mm}$ square window in the occipital bone to access the abducens nucleus through the intact cerebellum. Finally, a dental acrylic pedestal with embedded bolts and selftapping screws was constructed to immobilize the head during recording, and to attach electrical connectors for the eye coils and stimulating electrodes. Postoperative care was provided daily throughout the experiment. During the initial $3 \mathrm{~d}$, antibiotics (streptomycin and penicillin, 20,000 I.U./kg $\cdot$ d, i.m.), and analgesics (pirazolone, $0.1 \mathrm{~g} / \mathrm{kg} \cdot \mathrm{d}$, i.m.) were administered. The eyes and the skin around the implanted sockets were also cleaned if needed with sterile saline and instilled with antibiotics (gentamicin sulfate). During the postoperative period the animal was adapted to the feline restraining system by seating the animal for periods of 20 min during the aseptic cleaning of the recording chamber and calibration of eye movements.

Chronic recordings. Control recording sessions started $10 \mathrm{~d}$ after surgery. The animal was gently restrained in a fabric bag and placed in a Plexiglas cradle inside the magnetic field search-coil (Robinson, 1963) (CNC Engineering). Extracellular recordings were made with glass micropipettes pulled with long shanks $(30 \mathrm{~mm})$, and tips beveled to a resistance of 1-2 $\mathrm{M} \Omega$ when filled with $2 \mathrm{M} \mathrm{NaCl}$. The left abducens nucleus was located with the aid of the antidromic field potential produced by electrical stimulation of the ipsilateral VIth nerve. Abducens motoneurons were selectively identified by their antidromic and collision testing from the VIth nerve. Abducens internuclear neurons were selectively identified antidromically from the electrode implanted in the contralateral medial longitudinal fascicle and excluded from this study. Extracellular neuronal activity was amplified and filtered at a bandwidth of 10 $\mathrm{Hz}-10 \mathrm{kHz}$ for digitalization purposes.

Lateral rectus muscle tension recordings. Total oculorotary force of the lateral rectus muscle was recorded using a buckle-type muscle force transducer (MFT) attached to the tendon, and stabilized with nonabsorbable sutures (Miller et al., 2002). The MFT consists of a stainless steel frame carrying two miniature semiconductor strain gauges, wired as a half-Wheatstone bridge, and positioned to average forces across the tendon and compensate for variations in temperature. The device was implanted without disinserting the muscle, by positioning it over the tendon, tenting the muscle up inside the frame and sliding a stainless steel pin through bearings on the frame and under the muscle (Fig. 1B,C). Braided Teflon-insulated leads (AS-631, Cooner Wire) exit the orbit under the scalp, to a socket cemented to the acrylic pedestal which is used to embed the leads of coils and stimulating electrodes in the animal and restrain the head movements. Each MFT was calibrated before implantation, and again after excision, to verify that its sensitivity had not changed. The MFT was connected to a strain gauge amplifier (model 2120A, Vishay Micro-Measurements). During the same surgery, two hook electrodes made of Teflon-insulated multistranded stainless steel wire were implanted in the belly of the lateral rectus muscle for electromyographic recordings. Their leads were passed subcutaneously toward a connector cemented in the dental acrylic pedestal.

Analysis of muscle dynamics, firing rate, and eye kinematics. Horizontal and vertical positions of both eyes, tension of the left lateral rectus muscle, and neuronal activity in the left abducens nucleus were recorded and digitally stored for off-line analysis (Power 1401, Cambridge Electronic Design Ltd.), along with spikes detected online using a window discriminator. Computer programs written in Matlab 6.5 displayed instantaneous firing frequency (i.e., the reciprocal of the interval between two adjacent spikes) and the positions of both eyes for the purpose of data selection. Relationships between neuronal firing rate [FR, in spikes/s $(\mathrm{sp} / \mathrm{s})]$ and horizontal eye position [EP, in degrees (deg)] and its derivatives (velocity and acceleration) were obtained by multiple linear regression to calculate neuronal sensitivity to eye position ( $k$, in sp/s per deg), velocity $\left(r_{s}\right.$, in sp/s per deg/s) and acceleration $\left(m\right.$, in sp/s per deg $\left./ \mathrm{s}^{2}\right)$, the ordinate intercept $\left(F_{0}\right.$, in $\left.\mathrm{sp} / \mathrm{s}\right)$ and the abscissa intercept [the recruitment threshold (Th), in deg]. When using a first-order model (Robin- 

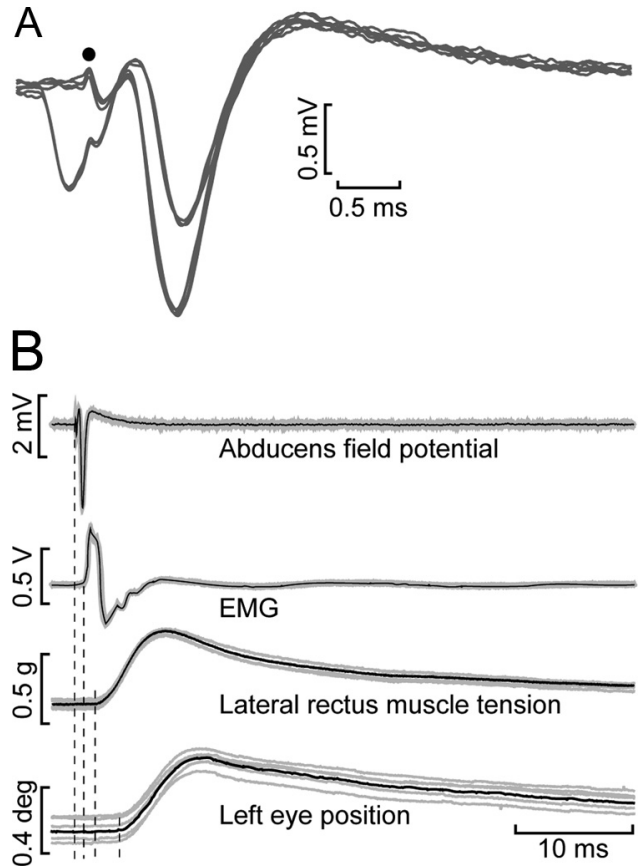

Figure 2. Electrical stimulation of the Vlth nerve. $\boldsymbol{A}$, Antidromic activation of an abducens motoneuron within the field potential after electrical stimulation (dot) to the abducens nerve. When the stimulus was conditioned by the presence of an orthodromic spike, the antidromic spike was occluded by the refractory period. $\boldsymbol{B}$, Electrical stimulation of the abducens nerve produced the antidromic abducens field potential followed by an electromyographic (EMG) compound potential in the muscle, followed by the initiation of tension in the muscle and finally by the initiation of movement in the ipsilateral eye. Dashed vertical lines mark the onset of events.

son, 1970), firing rates during fixations were well fit by the equation $\mathrm{FR}=$ $k \cdot \mathrm{EP}+F_{0}$ (supplemental Fig. S1 A, available at www.jneurosci.org as supplemental material). Relationships between neuronal firing and eye velocity during saccades were obtained by linear regression after subtraction of the position component $(k \cdot \mathrm{EP})$ calculated from the previously measured sensitivity to eye position. That is, we fit the equation FR $k \cdot \mathrm{EP}=r_{\mathrm{s}} \cdot \mathrm{EV}+F_{0}$, where $r_{\mathrm{s}}($ in $\mathrm{sp} / \mathrm{s}$ per $\mathrm{deg} / \mathrm{s})$ is the neuronal sensitivity to eye velocity (EV) during saccades (in deg/s) (supplemental Fig. $S 1 E$, available at www.jneurosci.org as supplemental material). The lead time of the motoneuron with respect to eye movement was estimated to be $5 \mathrm{~ms}$. This value was in accordance with the physiological measurements of latency for eye movements after abducens nerve stimulation (Fig. $2 B$ ). The procedure consisted in shifting in the eye movements during saccades in $1 \mathrm{~ms}$ increments in relation to the firing rate to produce the best fit by regression analysis. Once the latency period was determined, it was applied uniformly to all the data.

Firing rate was also related to parameters of lateral rectus muscle tension to obtain sensitivities to the tension $(p$, in $\mathrm{sp} / \mathrm{s} / \mathrm{g})$ and to the first derivative of tension ( $q$, in spikes/s per $\mathrm{g} / \mathrm{s}$ ). Regression models included those derived by Robinson (1963), Fuchs et al. (1988), the first-order simplification of the former (Robinson, 1970) as explained above, and mixed models containing signals related to both eye position and muscle force (present data).

The relationships between muscle tension and either eye position or firing rate were exponential, with exponential constants denoted $\alpha$ and $\beta$, respectively (supplemental Fig. $\mathrm{S} 1 B, C$, available at www. jneurosci.org as supplemental material). The linear relationship between firing rate and the first derivative of tension during saccades yielded a slope $r_{\mathrm{t}}$ (in spikes/s per g/s). Finally, for each cell during the slide phase after saccades we computed the decay time constants of muscle tension $\left(\tau_{\mathrm{MT}}\right)$ and firing rate $\left(\tau_{\mathrm{FR}}\right)$, and from at least $12 \mathrm{such}$ measurements a ratio, $S$, was calculated to characterize each motoneuron (supplemental Fig. $S 1 D$, available at www.jneurosci.org as supplemental material).
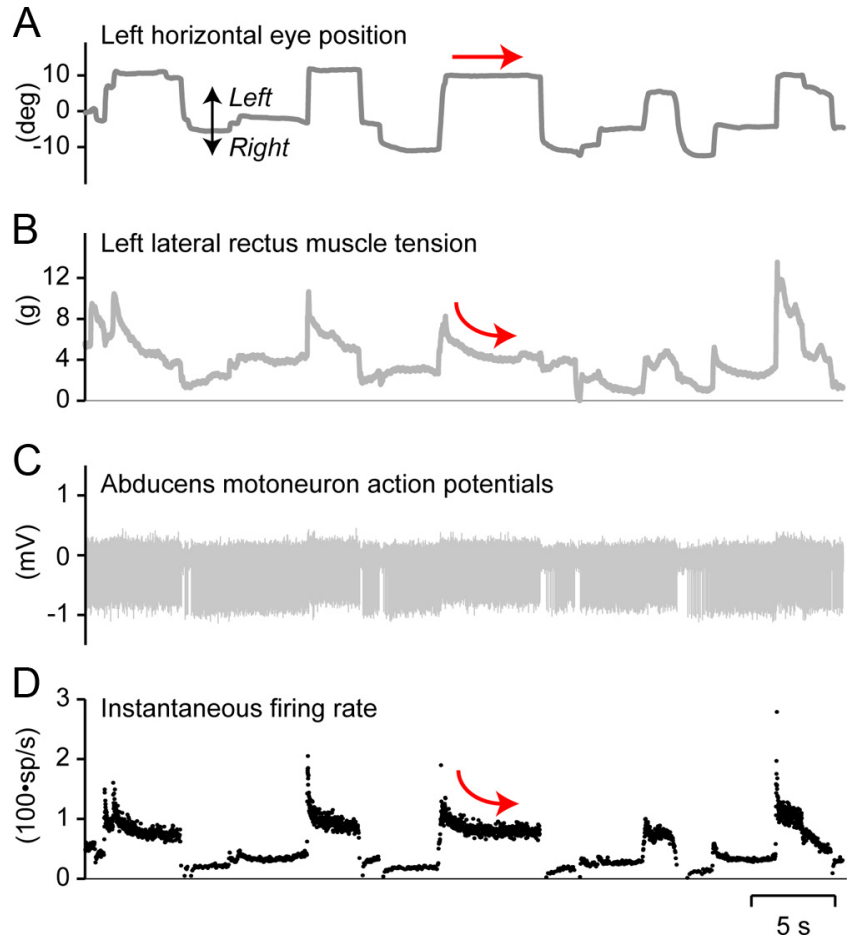

Figure 3. Firing frequency of abducens motoneurons during spontaneous eye movements. The unit was simultaneously recorded with both the eye position, using the field coil search technique, and the lateral rectus muscle tension, using a strain gauge recorder (called muscle force transducer). Note how tension resembles precisely the fine variations in firing frequency profile during steady eye fixations (arrows).

Cluster analysis. Cluster analysis is a statistical technique that identifies sample groupings in a multidimensional space. We considered that our motoneurons might fall into tonic, tonic-phasic and phasic groups according to signal content, following previously published descriptions (Henn and Cohen, 1972), and used K-means clustering to extract a predetermined number of clusters ( 3 in the present case) using reverse ANOVA to minimize variability within clusters and maximize variability between clusters (Daly et al., 1995).

\section{Results}

Is motoneuron firing related to eye position or muscle tension? Sixty two motoneurons were analyzed during spontaneous eye movements. Motoneurons were identified with antidromic activation from the abducens nerve and collision testing (Fig. 2A). Electrical stimulation of the abducens nerve produced the antidromic field in the abducens nucleus. The period of latency from the stimulation time to the beginning of the electromyographic spike was $1 \mathrm{~ms}$, and the increase in muscle tension occurred at $2-2.5 \mathrm{~ms}$, whereas the ipsilateral eye movement occurred at $4-5$ ms after the shock to the nerve (Fig. $2 B$ ).

During periods of spontaneous eye fixation, well isolated abducens motoneurons (Fig. 3C,D) monotonically increased their tonic firing in the on-direction, and decreased firing in the offdirection. During saccades, motoneurons fired briskly in the ondirection, and reduced firing or paused in the off-direction. Motoneurons also showed a slide transition between burst and tonic firing. MFT force signals during spontaneous eye movements (Fig. $3 B$ ) appeared to closely follow motoneuronal firing (Fig. 3D). Most striking was the similarity between the slide phase of motoneuron firing after on-directed saccades and the slide phase of muscle tension (Fig. $3 B, D$, curved arrows), which was not reflected in eye position (Fig. $3 A$, straight arrow). Subtle and 
small variations in motoneuron firing during fixations were reflected in MFT force signals, but not in eye position.

Each study of motoneuron firing has shown that the mean firing rate during stationary fixation is a linear function of eye position (Fig. 4A; supplemental Fig. $\mathrm{S} 1 A$, available at www.jneurosci.org as supplemental material; Table 1, first column), and all motoneurons we studied followed this rule. Namely, Ths were always positively correlated with eye position sensitivities $(k)$, thus, indicating the higher the recruitment threshold, the higher the eye position sensitivity (Fig. 4B). Muscle force was an exponential function of eye position, indicating that morethan-linearly increasing force was needed to maintain eccentric eye position in the orbit (Fig. 4C; supplemental Fig. S1B, available at www.jneurosci.org as supplemental material). We fitted these data by the equation $\mathrm{MT}=A_{\mathrm{MT}} \cdot e^{\alpha} \cdot \mathrm{EP}$, where MT is muscle tension, and EP is eye position. The exponential parameter $\alpha$ averaged $0.07 \mathrm{deg}^{-1}$ (Fig. 4D). Muscle tension was an exponential function of firing rate (Fig. $4 E$; supplemental Fig. S1C, available at www. jneurosci.org as supplemental material), $\mathrm{MT}=\mathrm{B}_{\mathrm{MT}} \cdot \mathrm{e}^{\beta} \cdot \mathrm{FR}$, with FR being the motoneuronal firing rate. The averaged $\beta$ value was $0.016 \mathrm{~s}$ for our sample of motoneurons (Fig. $4 F$ ). This finding indicated that the motoneuron firing rate correlates linearly with eye position but not with muscle tension during stationary eye fixations. As we show below, this latter exponential relationship can be explained by recruitment of other motoneurons, as the firing rate of the recorded motoneuron increased.

\section{Ensemble innervation determines muscle force}

We next measured the force produced by electrical stimulation of the abducens nerve under auxotonic conditions, that is, when the muscle shortens against the physiological load of other orbital tissues and the antagonist muscle. We evoked functional innervation of the muscle by increasing the frequency of electrical stimulation (from 40 to $200 \mathrm{~Hz}$ ) of the sixth nerve at supramaximal current intensity (twice the mechanical response threshold). Our data showed that muscle force increased with evoked innervation according to a power law (Fig. $5 A$ ). To estimate the physiological innervation-the total firing rate output of the motoneuron pool-we computed the sum of action potentials in our sample as a function of eye position. As shown in Figure $5 B$, abducens motoneurons tend to be recruited in order of increasing eye position sensitivity (see also Pastor and González-Forero, 2003). Calculated innervation (Fig. $5 C$, blue line) followed a power law (Fig. $5 C$, red line) in the recruitment range (Fig. $5 C$, arrows), and was linear beyond, suggesting that the force needed to overcome increasing orbital stiffness in eccentric gaze is produced by re-
B

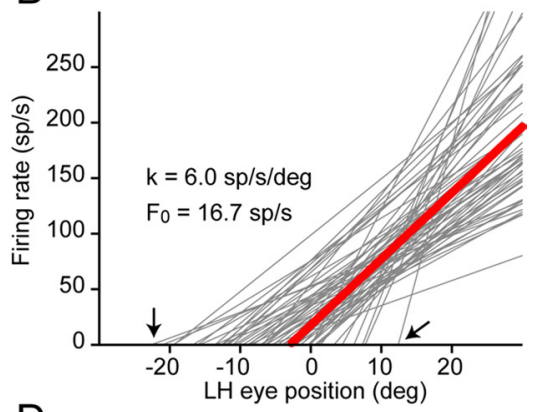

D

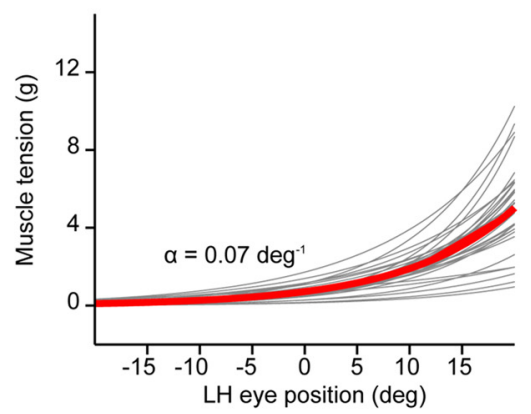

$\mathrm{F}$

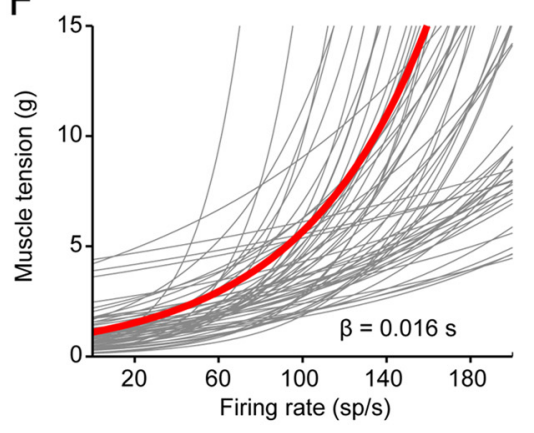

Figure 4. Individual motoneuron firing rates, eye position, and muscle force during steady fixation. $\boldsymbol{A}$, The linear relationship of FR to EP (LH, horizontal position of left eye, abduction positive) of an abducens motoneuron obtained during steady fixation demonstrates the motoneuronal sensitivity to eye position ( $k$, in sp/s per deg) and the recruitment threshold or abscissa intercept motoneurons and dat also supplemental Figure $\mathbf{S 1}$ (available at www.jneurosci.org as supplemental material).

cruitment of high-threshold neurons (Fig. 4B), which indeed tend to have high eye position sensitivities (Fig. $5 B$ ).

\section{Scaling of tonic and phasic signals in the pool of abducens motoneurons}

We sought to determine whether our pooled motoneurons fell into distinct groups according to their discharge characteristics. We considered whether cells could be clustered into tonic, tonicphasic and phasic groups (Henn and Cohen, 1972; Dieringer and Precht, 1986; Ugolini et al., 2006; Ying et al., 2008) by using $K$-means clustering with $K=3$ to explore a multidimensional space defined by the following six variables: eye position sensitivity $(k)$, Th, the ratio of firing rate to tension decay time constants ( $S$ ) (see supplemental Fig. S1 $D$, available at www.jneurosci.org as supplemental material), the exponent of the relationship of muscle force to unit firing rate $(\beta)$, and the eye velocity and tension derivative sensitivities $\left(r_{\mathrm{s}}\right.$ and $r_{\mathrm{t}}$; see Table 1 and supplemental 
Table 1. Eye movement- and tension-related parameters of abducens motoneurons

\begin{tabular}{|c|c|c|c|c|c|c|c|}
\hline & $N$ & $k$ (sp/s per deg) & Th (deg) & $\beta \cdot\left(10^{-3}\right)(\mathrm{s})$ & S(adim.) & $r_{\mathrm{s}}(\mathrm{sp} / \mathrm{s}$ per deg/s) & $r_{\mathrm{t}}(\mathrm{sp} / \mathrm{s}$ per deg/s) \\
\hline Group 1 & 23 & $8.9 \pm 1.0^{*}$ & $1.3 \pm 0.8^{*}$ & $10.7 \pm 1.2^{*}$ & $0.37 \pm 0.04^{*}$ & $0.78 \pm 0.06^{*}$ & $1.19 \pm 0.12^{\dagger}$ \\
\hline Group 2 & 24 & $4.5 \pm 0.2$ & $-6.8 \pm 0.5^{*}$ & $21.4 \pm 2.1$ & $0.60 \pm 0.06^{*}$ & $0.51 \pm 0.05$ & $0.95 \pm 0.14$ \\
\hline Group 3 & 15 & $4.1 \pm 0.3$ & $-15.4 \pm 0.9^{*}$ & $17.1 \pm 1.5$ & $0.96 \pm 0.09^{*}$ & $0.49 \pm 0.04$ & $0.53 \pm 0.07$ \\
\hline Total & 62 & $6.0 \pm 0.5$ & $-5.9 \pm 0.9$ & $16.4 \pm 1.2$ & $0.60 \pm 0.04$ & $0.61 \pm 0.03$ & $0.94 \pm 0.08$ \\
\hline
\end{tabular}

Values are means \pm SEM. Asterisks and dagger indicate significant differences with the other groups and with group 3, respectively (one-way ANOVA, Holm-Sidak method for post hoc comparisons, $p<0.05$ ). adim., Adimensional.

A

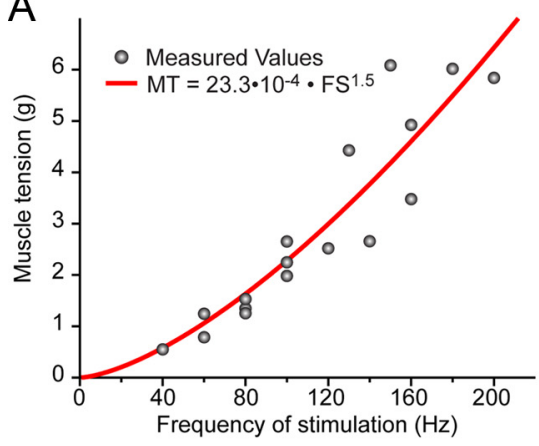

B

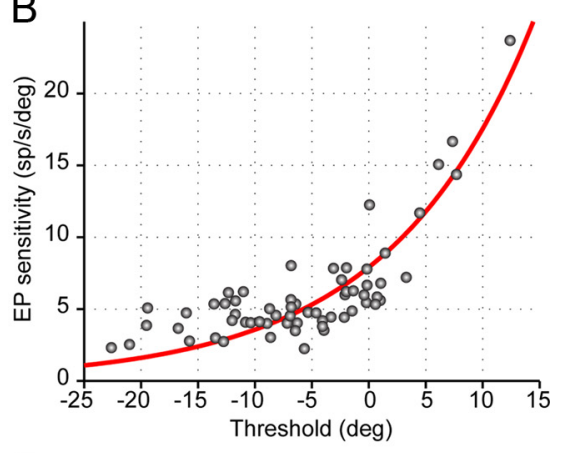

C

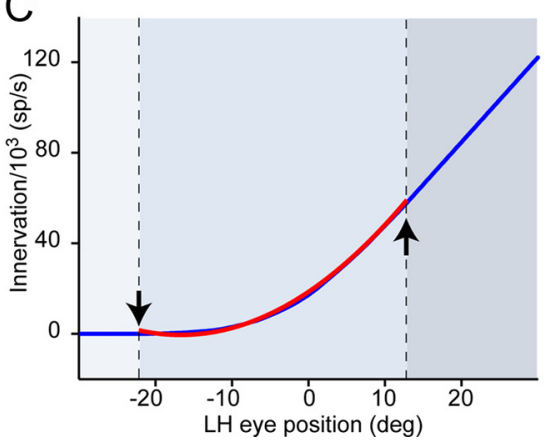

Figure 5. Innervation is a precise measurement of muscle tension. $\boldsymbol{A}$, Muscle tension (MT) as a function of frequency of stimulation (FS) applied to the abducens nerve. $\boldsymbol{B}$, Relationship between eye position sensitivity and threshold for the sample of abducens motoneurons. The fitted equation (red line) is EP sensitivity $=7.9 \cdot e^{0.08 \cdot \text { Th }}(r=0.86, p<0.001)$. C, Computation of innervation as the sum of action potentials in the abducens nerve (blue line) computed from the population presented in $\boldsymbol{B}$. Arrows indicate eye positions where the first and the last motoneuron in our sample were recruited. Innervation ( $/$ ) follows a power law $\left(I=6.8 \cdot \mathrm{EP}^{2}+\right.$ $226.8 \cdot E P+1853 ; r=0.99, p<0.001$, red line) in the recruitment range (arrows) and then becomes linear once all motoneurons are recruited.

Fig. S1E, available at www.jneurosci.org as supplemental material). Our 62 sampled cells were classified into three clusters of 23 (37.1\%), $24(38.7 \%)$ and $15(24.2 \%)$ cells (groups 1, 2 and 3, respectively).

Group 1 was significantly different from group 3 in all 6 variables, and significantly different from group 2 in 5 of 6 variables. Group 1 cells had high eye position sensitivity $(k)$, high Th, and high neuronal eye velocity sensitivity $\left(r_{\mathrm{s}}\right)$, these being generally
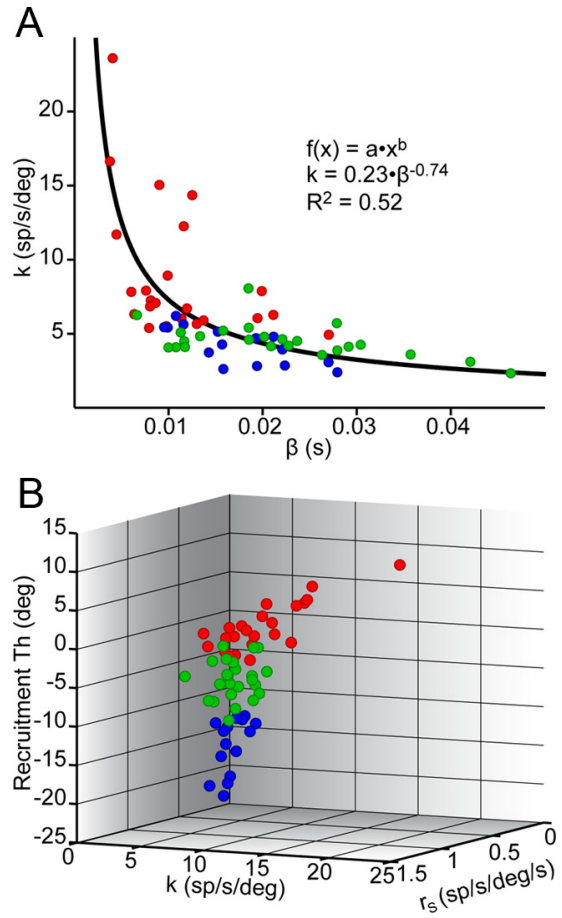

Figure 6. Are tonic and phasic signals represented as a continuum in the abducens motor pool? $A$, A scatterplot of $k$ versus $\beta$ shows that motoneurons of group 1 (red), group 2 (green), and group 3 (blue) have overlapping values. Calibrations are, from top to bottom, $5 \mathrm{deg}$ for eye position, $8 \mathrm{~g}$ for tension, $100 \mathrm{sp} / \mathrm{s}$ for firing rate, and $0.5 \mathrm{~s}$ for the time bar. $\boldsymbol{B}$, A scatterplot of $k$, $r_{s}$ and Th also showed continuity.

correlated (Fig. 6B; Table 1) Thus, neurons with high $k$ also had high $r_{\mathrm{s}}(r=0.73)$ and high Th $(r=0.76$; Fig. 6B). Group 1 cells also had high muscle force derivative sensitivity $\left(r_{\mathrm{t}}\right)$, which on the basis of the present study is correlated with $r_{s}$, and low ratios of firing rate to tension decay time constants (low $S$, see below), meaning that firing rates decayed quickly relative to force (Table 1 ). All these characteristics suggest that group 1 of motoneurons might be labeled as "phasic". Low $\beta$ values were correlated with neurons of higher eye position sensitivity $(k)$. Therefore, plotting $k$ versus $\beta$ showed an inverse relationship (Fig. $6 A$ ). The $\beta$ values of group 1 were low, indicating that these motoneurons with relatively modest changes in firing produced rapidly changing forces. Groups 2 and 3 were statistically distinguishable on Th and $S$ only, with group 3 showing the lowest Ths and highest $S$ ratios (Table 1). Group 3, characterized by its tonic profile, showed lower $\mathrm{Th}$, indicating that motoneurons belonging to this group were recruited first, had a larger $S$ indicatory of a longer postsaccadic slide after bursts, and a smaller $r_{\mathrm{s}}$ and $r_{\mathrm{t}}$ than group 1 . This in turn indicated less sensitivity to eye velocity and muscle tension during saccades (Table 1). Thus, 3 groups of abducens motoneurons can be distinguished, two groups quite clearly, on parameters characterizing the pulse, slide and step phases. A representative example of each type of motoneuron is illustrated in Figure 7. 

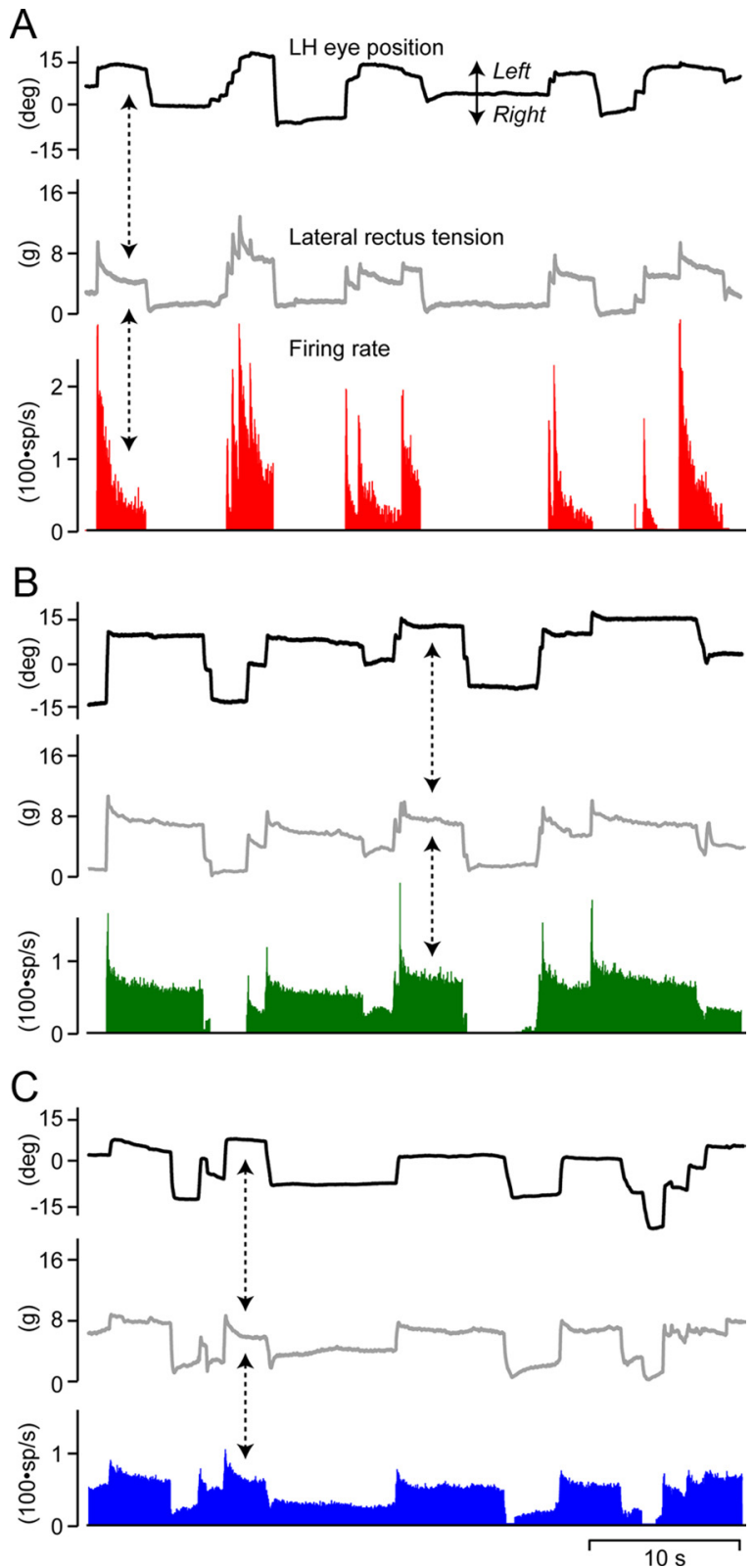

Figure 7. $\boldsymbol{A}-\boldsymbol{C}$, Firing rate behavior of representative motoneurons from group 1 ( $\boldsymbol{A}, \mathrm{red})$, group 2 ( $\boldsymbol{B}$, green), and group 3 ( $\boldsymbol{C}$, blue). Note differences in cell behavior from more phasic in $\boldsymbol{A}$ to more tonic in $\boldsymbol{C}$ during similar muscle tension and eye excursions (dashed arrows).

\section{Firing properties of abducens motoneurons during the postsaccadic slide}

The slide phase of muscle tension (Fig. $8 \mathrm{~A}$, blue trace) after saccades occurred in the absence of comparable changes in eye position (gray trace), as did the slide phase of firing rate (Fig. $8 \mathrm{~B}$ ). The postsaccadic slide in muscle tension or firing rate were fitted by exponential functions (Fig. $8 A, B$; supplemental Fig. S $D$, available at www.jneurosci.org as supplemental material) whose exponents were named $\tau_{\mathrm{MT}}$ and $\tau_{\mathrm{FR}}$, respectively. When we plotted $\tau_{\mathrm{MT}}$ versus $\tau_{\mathrm{FR}}$ we obtained linear regression lines with correlation coefficients $>0.65$ for all our 62 sampled motoneurons. The slopes of the regression lines (the $S$ parameter) varied widely (Fig. 8C). That is, there were cells with high $S$ (firing rate decayed slowly compared with tension), which corresponded to cells that had weak bursts, and cells with short time constants in the slide phase of firing, which showed strong saccadic bursts. The finding that each motoneuron had a characteristic $S$ value suggests that these cells encoded the slide phase of muscle force. We looked for clustering of motoneurons according to the variable $S$, and as indicated in Figure $8 D$, there was a tendency for neurons with high recruitment thresholds (group 1, red dots) to have low $S$ ratios and for those with low thresholds (group 3, blue dots) to have high $S$ ratios, with group 2 neurons (green dots) being intermediate. However, as Figure $8 D$ makes clear, there was substantial overlap among groups. The analysis showed that $S$ correlated well with recruitment threshold $(r=0.74 ; p<0.001)$ reinforcing the idea that the slide phase is a separate signal computed by motoneurons.

\section{Does firing rate predict muscle tension?}

We tested firing rate as a predictor of muscle tension using as a basis the classical second order model, $\mathrm{M} 1: \mathrm{FR}=k \cdot E+r_{\mathrm{s}} \cdot E^{\prime}+$ $m \cdot E^{\prime \prime}+F_{0}$. Our second model added to this a tension element, $\mathrm{M} 2: \mathrm{FR}=k \cdot E+r_{\mathrm{s}} \cdot E^{\prime}+m \cdot E^{\prime \prime}+F_{0}+\mathrm{pT}$. Our third model reflected only muscle tension, $\mathrm{M} 3: \mathrm{FR}=p \cdot T+q \cdot T^{\prime}+F_{0}$. A final model contained a nonlinear term to explain the slide in firing M4: $\mathrm{FR}=k \cdot E+r_{\mathrm{s}} \cdot E^{\prime}+m \cdot E^{\prime \prime}+F_{0}-c \cdot \mathrm{FR}^{\prime}$ (Fig. 9). Calculation of the models was based on eye movements and tension and the model parameters were obtained by linear regression analysis using the residuals to inspect the goodness of fit of the models. Models 1 and 4 poorly fitted the slide-phase firing associated with on-directed (Fig. 9, arrows in M1 and M4) and offdirected saccades (Fig. 9, crossed arrows in M1 and M4). Models 1 and 4 were also unable to fit small variations in firing rate produced during fixations (Fig. 9, arrowheads in M1 and M4). In contrast, models 2 and 3 provided good fits to the slide-phase firing and followed small firing rate fluctuations (corresponding to the fact that small variations in firing were seen in force, but not in eye position; compare tension with firing rate in Fig. 9). Models 2 and 3 continued to follow small variations in firing rate during fixations lasting $>5 \mathrm{~s}$.

We evaluated the 4 models by computing coefficients of determination over periods of time following saccades, increasing in 100 ms steps, using 27 epochs from 12 cells in 3 animals. Each epoch contained a saccade and a fixation lasting for at least $3 \mathrm{~s}$ (Fig. 10A). The coefficients of determination of the multiple regression analysis for each model are plotted in Figure $10 \mathrm{~B}$, which shows that the fit of all models decayed with time, but that models 1 and 4, which were based solely on eye position, decayed the most. ANOVA showed that models 2 and 3 were equally efficient, and that after 1 and $1.6 \mathrm{~s}$, respectively, the efficiencies of models 1 and 4 were significantly lower. This result indicated that models containing tension-derived parameters were more efficient in explaining firing rate.

\section{Discussion}

\section{On the prediction of force by motoneurons}

We found lateral rectus muscle force rises nonlinearly with motoneuronal firing rate which is similar to the relationship between muscle tension and eye position (Fig. 4C,E) (see also Collins, 1971, their Fig. 8). We also showed that force generated by the lateral rectus muscle during auxotonic conditions varies with the frequency of stimulation (Fig. 5A). Since force is produced by an ensemble innervation to the entire muscle, it is reasonable to compute total innervation as the sum of action potentials in the abducens nerve during the recruitment of neurons with progressively higher eye position sensitivity (Pastor and GonzálezForero, 2003) explaining the accelerating rise in tension with eye eccentricity (Fig. 5C). 
A
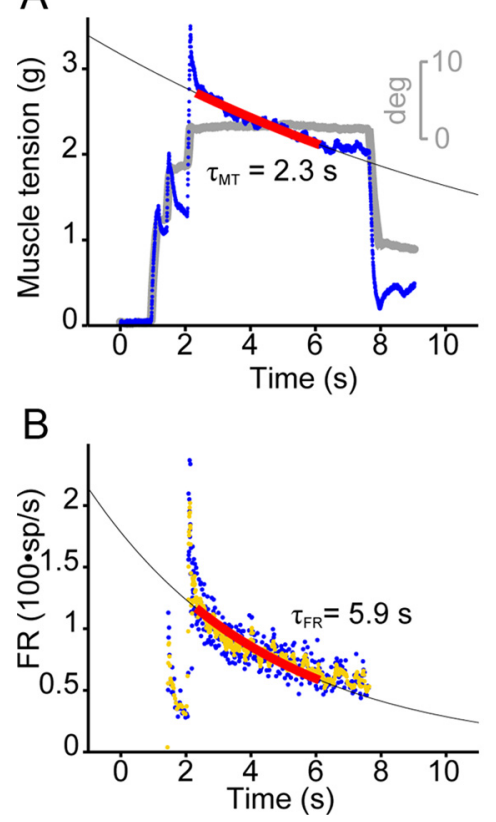

Figure 8. Postsaccadic slide as a distinct discharge characteristic. $\boldsymbol{A}$, Muscle tension (blue) during a saccade demonstrates a postsaccadic slide in tension despite the fact that the eye position (gray) is stationary. Red line is the exponential fit of the muscle tension data. $\boldsymbol{B}$, Firing rate (blue dots) demonstrates also a postsaccadic decay for the same saccade shown in $\boldsymbol{A}$. Yellow dots are the 5 point floating average of the data and the red line is the exponential fit of the firing rate data. $C$, For each motoneuron a relationship (gray lines) can be obtained between the time constants of the postsaccadic slide in firing $\left(\tau_{\mathrm{FR}}\right)$ and its corresponding decay in tension $\left(\tau_{\mathrm{MT}}\right)$. This result indicates that the postsaccadic slide is another signal conveyed by motoneurons that can be characterized as the slope of a regression line (sensitivity to postsaccadic slide or parameter $S$; adimensional). The cyan line is the line of slope 1 , which is close to the populational average (red line). $\boldsymbol{D}$, Motoneurons with shorter time constants for the postsaccadic slide (lower $S$ ) are also recruited later $(r=0.74 ; p<0.001)$. See also supplemental Figure $S 1$ (available at www.jneurosci.org as supplemental material). position, the neural integrator, in either the undershooting or overshooting direction (Major et al., 2004a,b). Our results indicate that the slide is actually encoded by motoneurons rather than being a passive decay from the burst to the tonic firing. In light of the known adaptability of the slide signal, it is reasonable to argue that it is conveyed to motoneurons, albeit not from a special structure dedicated to process the slide (Optican and Miles, 1985), but as a characteristic of the firing of neurons that form part of the output of the neural integrator (Major et al., 2004b). Slide-like firing can be observed in the discharge of neurons in the flocculus and surrounding the medial longitudinal fasciculus (Miles et al., 1980; Delgado-García et al., 1986b, 1989; Iwamoto et al., 1990); however, a nucleus remains to be identified to explain the origin of the slide signal. The intrinsic properties of the motoneuronal membrane appear to be excluded, because adaptation to current pulses has time constants much shorter than those of the slide (Baker and Precht, 1972; Barmack, 1974; Grantyn and Grantyn, 1978; Durand, 1989). We, therefore, propose that the slide is an essential neural signal processed and adapted within the preoculomotor circuitry before conveyed to the motoneurons (Major et al., 2004).
Our findings suggest that the abducens motor pool applies a nonlinear innervation function to the lateral rectus muscle that in turn, results in a linear response with steady fixation. By contrast, current mechanical models explain the firing of motoneurons based on Robinson's (1963) study relating eye movement kinematics (position, velocity, and acceleration) to muscle dynamics (tension and its first derivative) (Optican and Miles, 1985; Fuchs et al., 1988; Stahl and Simpson, 1995). This model approach does not address how plant nonlinearities are compensated to produce a linear eye movement. Several attempts have been made however, as pointed out by Collins (1975) and more recently by Sylvestre and Cullen (1999), the push-pull nature of the agonist-antagonist pair cancels muscle nonlinearities.

\section{On the postsaccadic slide signaling by motoneurons}

The time constants of the slide-phase decay of motoneuron firing and lateral rectus muscle tension were linearly related indicating that its ratio, $S$, was a measure of the motoneuronal responsiveness during the slide. And thus we propose that the slide is actually encoded as a distinct signal by motoneurons. It has been previously shown that the time constant of the slidephase firing is linearly related to the amplitude of the pulsestep mismatch (Pastor et al., 1991) and also that the eye can be trained to either undershoot or overshoot immediately after the saccade by means of behavioral paradigms that shifted the image after the saccade (Kapoula et al., 1987, 1989; Optican and Miles, 1985). This postsaccadic drift adaptation can lead to functional changes in the output of the generator of eye

\section{On the division of labor by motoneurons}

Abducens motoneurons could be classified into continuous overlapping groups of cells, with some being relatively phasic (group 1) and associated with large muscle forces, and others moderately tonic (Groups 2 and 3). A clear scaling of Th and slide sensitivity $(S)$ across groups (Figs. $6 \mathrm{~B}, 8 \mathrm{D}$; Table 1 ) indicated that abducens motoneurons could be classified into phasic (group 1), tonic (group 3) and intermediate tonic-phasic characteristics (group 2 ). As eye eccentricity increased, the first motoneuronal group (3) to be recruited had low eye position and eye velocity sensitivity while the last recruited group (1) had high $k$ and $r_{s}$, in good agreement with the finding that these two parameters are positively correlated in abducens motoneurons. Our findings highlight the possibility that the tonic neurons in the earliest recruitment range might include small cells contacting the multiply innervated fibers, although it is also possible that the smallest motoneurons were not sampled. To the contrary, motoneurons in groups 2 and 3 would contact singly innervated muscle fibers (Büttner-Ennever et al., 2001, 2002; Ugolini et al., 2006). We found that most of the parameters of group 1 motoneurons (Table 1) clearly differed from the other two groups (2 and 3). Discharge characteristics of group 1 motoneurons were more suitable for a correlation with tension than with eye position. The high $r$ sensitivity and small $S$ would result in brisk bursts of action potentials during saccades with a noticeable postsaccadic decay that closely resembles the shape of muscle force.

We have recently shown that oculomotor motoneurons are endowed with neurotrophin receptors (Benítez-Temiño et al., 2004) and that the administration of neurotrophins to axoto- 

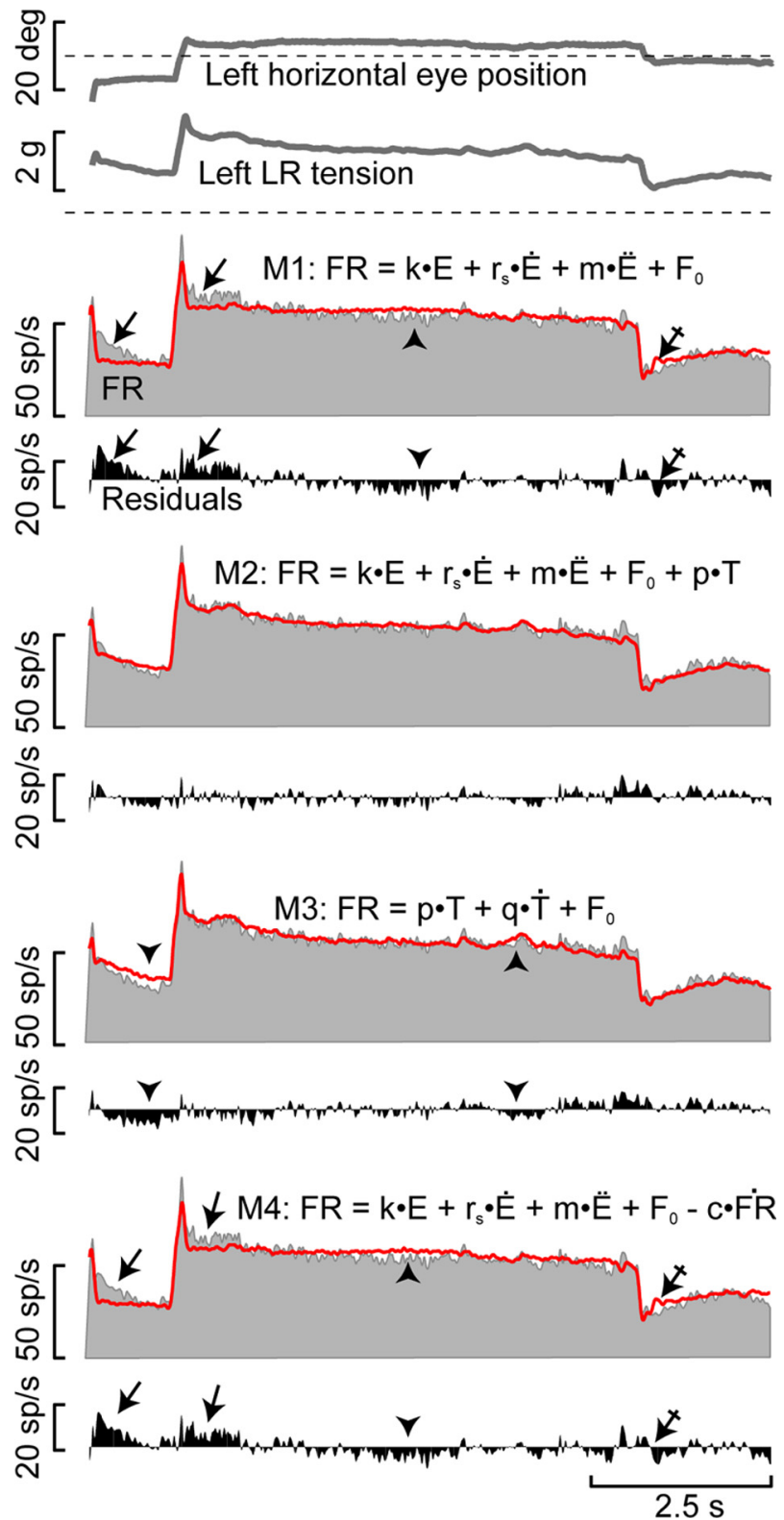

Figure 9. Models for the prediction of the activity of abducens motoneurons. From top to bottom, left horizontal eye position, lateral rectus muscle tension, and firing rate of an abducens motoneuron (FR, gray) during spontaneous eye movements are shown. The predicted firing rate for each model is shown (red line) on top of the original firing rate. Below each prediction the residuals, i.e., original minus predicted firing, are plotted. Model equations M1 through M4 are just above corresponding predictions. Note that model 1, based on eye movement signals (Van Gisbergen et al., 1981), as well as model 4, based on eye movement signals and the derivative of the firing rate (Robinson, 1964), do not predict effectively either the postsaccadic slide in both directions (activation, arrows; inactivation, crossed arrows) or the slow decay observed along the fixation (arrowheads). Estimations from models 2 and 3 that use tension ( $T$ ) terms, on the other hand, are closer to the original discharge during postsaccadic slides, as is demonstrated by the small residuals in these regions. While model 2 includes eye movement parameters plus tension, model 3 only uses tension and its first derivative.

mized abducens motoneurons restores normal discharge characteristics (Davis-López de Carrizosa et al., 2008, 2009, 2010). These results indicate that motoneurons are trophically dependent on their target (for review, see Benítez-Temiño et al., 2005). The neurotrophins BDNF and NT-3 had complementary roles in regulating the phenotype of abducens motoneurons. BDNF enhanced the tonic firing whereas NT-3
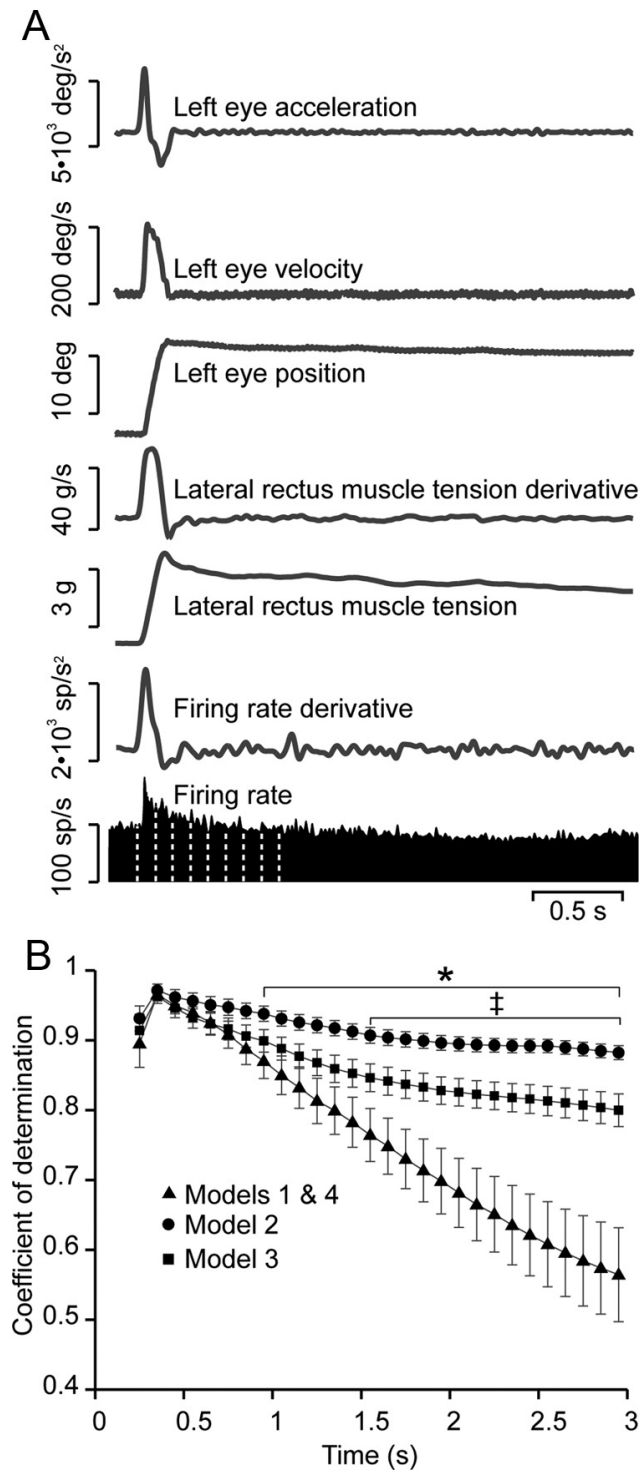

Figure 10. Statistical analysis of the models. The goodness of the prediction of each model, measured as the coefficient of determination obtained by multiple regression, was tested using epochs of increasing duration. $\boldsymbol{A}$, Epochs started $200 \mathrm{~ms}$ before an on-directed saccade and lasted $3 \mathrm{~s}$. The models were first tested on the initial $250 \mathrm{~ms}$ of the epoch and then on successive steps of $100 \mathrm{~ms}$ each. $\boldsymbol{B}$, Coefficients of determination vs time for the different models. № differences were found between coefficients of determination from models 1 and 4 . However, as the period used on the regression increases, the goodness of models 1 and 4 decreases to a greater extent than the coefficient of determination of models 2 and 3 . One second after the time interval of analysis started, the goodness of the prediction made by models 1 and 4 was significantly different from that of model $2\left({ }^{*} p<0.05\right.$, two-way ANOVA) and, $600 \mathrm{~ms}$ after, was also different from that of model $3\left({ }^{\ddagger} p<0.05\right.$, two-way ANOVA). No significant differences were found in the goodness of fit between models 2 and 3 ; however, the coefficient of determination values were always lower for the latter model.

enhanced the phasic firing of motoneurons. Firing characteristics tuned in complementary fashion by gradients of neurotrophins or by activation of complementary neurotrophin receptors have recently been described (Adamson et al., 2002; Luther and Birren, 2009). Thus, it can be proposed that different neurotrophins provided by the distinct types of muscle fiber couls influence the discharge characteristics of abducens motoneurons from the very phasic to the very tonic patterns as found in the present work. 


\section{References}

Adamson CL, Reid MA, Davis RL (2002) Opposite actions of brainderived neurotrophic factor and neurotrophin-3 on firing features and ion channel composition of murine spiral ganglion neurons. J Neurosci 22:1385-1396.

Aksay E, Gamkrelidze G, Seung HS, Baker R, Tank DW (2001) In vivo intracellular recording and perturbation of persistent activity in a neural integrator. Nat Neurosci 4:184-193.

Aksay E, Olasagasti I, Mensh BD, Baker R, Goldman MS, Tank DW (2007) Functional dissection of circuitry in a neural integrator. Nat Neurosci 10:494-504.

Baker R, Precht W (1972) Electrophysiological properties of trochlear motoneurons as revealed by IVth nerve stimulation. Exp Brain Res 14:127-157.

Barmack NH (1974) Saccadic discharges evoked by intracellular stimulation of extraocular motoneurons. J Neurophysiol 37:395-412.

Benítez-Temiño B, Morcuende S, Mentis GZ, de la Cruz RR, Pastor AM (2004) Expression of Trk receptors in the oculomotor system of the adult cat. J Comp Neurol 473:538-552.

Benítez-Temiño B, de la Cruz RR, Tena JJ, Pastor AM (2005) Cerebellar grafting in the oculomotor system as a model to study target influence on adult neurons. Brain Res Brain Res Rev 49:317-329.

Büttner-Ennever JA, Horn AK, Scherberger H, D'Ascanio P (2001) Motoneurons of twitch and nontwitch extraocular muscle fibers in the abducens, trochlear, and oculomotor nuclei of monkeys. J Comp Neurol 438:318-335.

Büttner-Ennever JA, Horn AK, Graf W, Ugolini G (2002) Modern concepts of brainstem anatomy: from extraocular motoneurons to proprioceptive pathways. Ann N Y Acad Sci 956:75-84.

Collins CC (1971) Orbital mechanics. In: The control of eye movements (Bach-y-Rita P, Collins CC, Hyde JE, eds), pp 283-325. New York: Academic.

Collins CC (1975) The human oculomotor control system. In: Basic mechanisms of ocular motility and their clinical implications (Lennerstrand E, Bach-Y-Rita P, eds), pp 145-180. New York: Pergamon.

Daly F, Hand DJ, Jones MC, Lunn AD, McConway KJ (1995) Elements of statistics, pp 538-543. New York: The Open University.

Davis-López de Carrizosa MA, Tena JJ, Benítez-Temiño B, Morado-Díaz CJ, Pastor AM, de la Cruz RR (2008) A chronically-implantable device for the controlled delivery of substances, the stimulation and the recording of activity in severed nerves. J Neurosci Methods 167:302-309.

Davis-López de Carrizosa MA, Morado-Díaz CJ, Tena JJ, Benítez-Temiño B, Pecero ML, Morcuende SR, de la Cruz RR, Pastor AM (2009) Complementary actions of BDNF and neurotrophin- 3 on the firing patterns and synaptic composition of motoneurons. J Neurosci 29:575-587.

Davis-López de Carrizosa MA, Morado-Díaz CJ, Morcuende S, de la Cruz RR, Pastor AM (2010) Nerve growth factor regulates the firing patterns and synaptic composition of motoneurons. J Neurosci 30:8308-8319.

Delgado-García JM, del Pozo F, Baker R (1986a) Behavior of neurons in the abducens nucleus of the alert cat-I. Motoneurons. Neuroscience 17:929-952.

Delgado-García JM, del Pozo F, Baker R (1986b) Behavior of neurons in the abducens nucleus of the alert cat-II. Internuclear neurons. Neuroscience 17:953-973.

Dieringer N, Precht W (1986) Functional organization of eye velocity and eye position signals in abducens motoneurons of the frog. J Comp Physiol 158:179-194.

Durand J (1989) Intracellular study of oculomotor neurons in the rat. Neuroscience 30:639-649.

Fuchs AF, Luschei ES (1970) Firing patterns of abducens neurons of alert monkeys in relationship to horizontal eye movement. J Neurophysiol 33:382-392.

Fuchs AF, Scudder CA, Kaneko CR (1988) Discharge patterns and recruitment order of identified motoneurons and internuclear neurons in the monkey abducens nucleus. J Neurophysiol 60:1874-1895.

Goldstein HP, Robinson DA (1986) Hysteresis and slow drift in abducens unit activity. J Neurophysiol 55:1044-1056.
Grantyn R, Grantyn A (1978) Morphological and electrophysiological properties of cat abducens motoneurons. Exp Brain Res 31:249-274.

Henn V, Cohen B (1972) Eye muscle motor neurons with different functional characteristics. Brain Res 45:561-568.

Iwamoto Y, Kitama T, Yoshida K (1990) Vertical eye movement-related secondary vestibular neurons ascending in medial longitudinal fasciculus in cat I. Firing properties and projection pathways. J Neurophysiol 63:902-917.

Kapoula Z, Hain TC, Zee DS, Robinson DA (1987) Adaptive changes in post-saccadic drift induced by patching one eye. Vision Res 27: 1299-1307.

Kapoula Z, Optican LM, Robinson DA (1989) Visually induced plasticity of postsaccadic ocular drift in normal humans. J Neurophysiol 61:879-891.

Luther JA, Birren SJ (2009) p75 and TrkA signaling regulates sympathetic neuronal firing patterns via differential modulation of voltage-gated currents. J Neurosci 29:5411-5424.

Major G, Baker R, Aksay E, Mensh B, Seung HS, Tank DW (2004a) Plasticity and tuning by visual feedback of the stability of a neural integrator. Proc Natl Acad Sci U S A 101:7739-7744.

Major G, Baker R, Aksay E, Seung HS, Tank DW (2004b) Plasticity and tuning of the time course of analog persistent firing in a neural integrator. Proc Natl Acad Sci U S A 101:7745-7750.

Miles FA, Fuller JH, Braitman DJ, Dow BM (1980) Long-term adaptive changes in primate vestibuloocular reflex. III. Electrophysiological observations in flocculus of normal monkeys. J Neurophysiol 43:1437-1476.

Miller JM, Robins D (1992) Extraocular muscle forces in alert monkey. Vision Res 32:1099-1113.

Miller JM, Bockisch CJ, Pavlovski DS (2002) Missing lateral rectus force and absence of medial rectus co-contraction in ocular convergence. J Neurophysiol 87:2421-2433.

Optican LM, Miles FA (1985) Visually induced adaptive changes in primate saccadic oculomotor control signals. J Neurophysiol 54:940-958.

Pastor AM, González-Forero D (2003) Recruitment order of cat abducens motoneurons and internuclear neurons. J Neurophysiol 90:2240-2252.

Pastor AM, Torres B, Delgado-García JM, Baker R (1991) Discharge characteristics of medial rectus and abducens motoneurons in the goldfish. J Neurophysiol 66:2125-2140.

Pastor AM, De la Cruz RR, Baker R (1994) Eye position and eye velocity integrators reside in separate brainstem nuclei. Proc Natl Acad Sci U S A 91:807-811.

Pastor AM, Davis-López de Carrizosa M, Morado-Díaz CJ, Miller JM, de la Cruz RR (2009) The encoding of muscle tension by discharge characteristics of cat abducens motoneurons. Soc Neurosci Abstr 39:356.6/Z16.

Robinson DA (1963) A method of measuring eye movement using a scleral search coil in a magnetic field. IEEE Trans Biomed Eng 10:137-145.

Robinson DA (1970) Oculomotor unit behavior in the monkey. J Neurophysiol 33:393-403.

Schiller PH (1970) The discharge characteristics of single units in the oculomotor and abducens nuclei of the unanesthetized monkey. Exp Brain Res 10:347-362.

Stahl JS, Simpson JI (1995) Dynamics of abducens nucleus neurons in the awake rabbit. J Neurophysiol 73:1383-1395.

Sterling P, Gestrin P (1975) Goldfish abducens motoneurons: physiological and anatomical specialization. Science 189:1091-1093.

Sylvestre PA, Cullen KE (1999) Quantitative analysis of abducens neuron discharge dynamics during saccadic and slow eye movements. J Neurophysiol 82:2612-2632.

Ugolini G, Klam F, Doldan Dans M, Dubayle D, Brandi AM, Büttner-Ennever J, Graf W (2006) Horizontal eye movement networks in primates as revealed by retrograde transneuronal transfer of rabies virus: differences in monosynaptic input to "slow" and "fast" abducens motoneurons. J Comp Neurol 498:762-785.

Van Gisbergen JA, Robinson DA, Gielen S (1981) A quantitative analysis of generation of saccadic eye movements by burst neurons. J Neurophysiol 45:417-442.

Ying HS, Fackelmann K, Messoudi A, Tang XF, Büttner-Ennever JA, Horn AK (2008) Neuronal signalling expression profiles of motoneurons supplying multiply or singly innervated extraocular muscle fibres in monkey. Prog Brain Res 171:13-16. 